\title{
Effects of the Metabotropic Glutamate Receptor Antagonist MCPG on Phosphoinositide Turnover and Synaptic Plasticity in Visual Cortex
}

\author{
Kimberly M. Huber, Nathaniel B. Sawtell, and Mark F. Bear \\ Department of Neuroscience, Howard Hughes Medical Institute, Brown University, Providence, Rhode Island 02912
}

\begin{abstract}
The neurotransmitter glutamate, in addition to activating ligandgated ion channels, also stimulates phosphoinositide (PI) hydrolysis in neurons by activating a group of G-protein-coupled metabotropic glutamate receptors (mGluRs). A role for mGluRs in synaptic plasticity originally was hypothesized based on the observation that the developmental decline in glutamate-stimulated PI turnover is well correlated with the decline in experiencedependent synaptic plasticity in visual cortex. Over the past few years, the compound $\alpha$-methyl-4-carboxyphenylglycine (MCPG) has been widely used to test the role of PI-coupled mGluRs in a number of types of synaptic plasticity, including long-term potentiation (LTP), long-term depression (LTD), ocular dominance plasticity in visual cortex, and the neural plasticity underlying learning
\end{abstract}

and memory. The conclusions of most of these studies were based on the assumption that MCPG blocks the actions of glutamate at Pl-coupled mGluRs in the cerebral cortex. Here we show that this assumption is not valid in visual cortex. Although MCPG does antagonize the actions of the synthetic mGluR agonist 1S,3R-aminocyclopentane-1,3-dicarboxylic acid, it fails to block PI turnover and changes in spike adaptation stimulated by glutamate, the endogenous mGluR ligand. In addition, we find that MCPG fails to block the NMDA receptor-dependent forms of LTP, LTD, and depotentiation in visual cortex.

Key words: visual cortex; metabotropic glutamate receptor; development; synaptic plasticity; long-term potentiation; longterm depression
Glutamatergic synapses in the visual cortex are modified by sensory experience. A central question concerns the mechanisms that underlie these synaptic modifications. Considerable circumstantial evidence points to the involvement of G-protein-coupled, metabotropic glutamate receptors (mGluRs) in visual cortical plasticity. Like experience-dependent plasticity, the coupling of mGluRs to intracellular second messenger systems in visual cortex is greatest during a critical period of early postnatal life (Dudek and Bear, 1989; Reid et al., 1996). A striking example is the developmental changes in glutamate-stimulated phosphoinositide (PI) hydrolysis, which are well correlated with developmental changes in visual cortical plasticity (Dudek and Bear, 1989). A consequence of PI turnover is the generation of two second messengers, diacylglycerol and phosphatidylinositol trisphosphate, leading in turn to activation of protein kinase $\mathrm{C}$ and the release of intracellular calcium stores (Berridge, 1984). Thus, it has been suggested that differences in the pattern or amount of mGluR-mediated PI turnover might account for the quantitative differences in synaptic plasticity at different ages (Dudek and Bear, 1989; Bear and Dudek, 1991).

Mechanistic studies of cortical plasticity have been aided considerably by the use of in vitro model systems. The best-studied model is the CA1 region of hippocampus, where both long-term synaptic potentiation (LTP) and depression (LTD) can be elicited with tetanic stimulation of presynaptic axons (Bear and Malenka, 1994). Recent work has shown that very similar forms of synaptic

\footnotetext{
Received July 15, 1997; revised Oct. 6, 1997; accepted Oct 9, 1997.

We thank Robert Patrick and Serena Dudek for helpful advice on the PI turnover assay, Alfredo Kirkwood for technical assistance with intracellular recordings, and Arnold Heynen and Barry Connors for comments on the manuscript.

Correspondence should be addressed to Dr. Mark Bear, Howard Hughes Medical Institute and Department of Neuroscience, Brown University, Providence, RI 02912. Copyright (C) 1997 Society for Neuroscience $0270-6474 / 97 / 180001-09 \$ 05.00 / 0$
}

plasticity are also present in the superficial layers of somatosensory and visual neocortex (Kirkwood et al., 1993; CastroAlamancos et al., 1995). In both CA1 and sensory neocortex, high-frequency stimulation can induce NMDA receptordependent LTP, and low-frequency stimulation can induce NMDA receptor-dependent homosynaptic LTD. The mechanisms of LTD and LTP apparently are well conserved, having been observed in the neocortex of many species, including humans (Chen et al., 1996). Of particular interest is the observation that in visual cortex there is a developmental decline in LTP and LTD that, like the decline in mGluR-mediated PI turnover, correlates well with the age-dependent loss of experiencedependent plasticity (Kirkwood et al., 1995; Dudek and Friedlander, 1996). Thus, the study of LTP and LTD potentially offers an opportunity to clarify the role of mGluRs in cortical plasticity.

Tests of the importance of mGluRs in synaptic plasticity became feasible with the introduction of the phenylglycine derivative $\alpha$-methyl-4-carboxyphenylglycine (MCPG). MCPG selectively blocks the PI turnover stimulated in the cerebral cortex by the mGluR agonist 1S,3R-aminocyclopentane-1,3-dicarboxylic acid (ACPD) (Birse et al., 1993; Eaton et al., 1993) and has been used widely as a reagent to study mGluR involvement in synaptic function. However, the effects of MCPG on LTP and LTD have been highly variable. Early reports indicated that tetanus-induced LTP (Bashir et al., 1993; Bortolotto et al., 1994), LTD (Bolshakov and Siegelbaum, 1994), and depotentiation (Bashir and Collingridge, 1994) in CA1 are all blocked by MCPG. However, more recent studies, including one performed in this laboratory (Selig et al., 1995), have shown that these forms of synaptic plasticity are readily induced in the presence of this drug (Chinestra et al., 1993; Manzoni et al., 1994; Thomas and O'Dell, 1995). Such variability is unusual because MCPG is believed to act simply as a competitive antagonist of cell surface mGluRs. One 
explanation for the variability is suggested by recent data showing that there are multiple forms of LTD in CA1 (Oliet et al., 1997). In any case, the data are clear that MCPG treatment does not reliably block NMDA receptor-dependent LTD and LTP in CA1. These results seemed to exclude the hypothesis that activation of MCPG-sensitive mGluRs is a requirement for induction of these forms of synaptic plasticity.

Because of the similarities between NMDA receptordependent LTD and LTP in CA1 and neocortex, we initially assumed that MCPG would also be without effect on synaptic plasticity in slices of visual cortex. It therefore came as a surprise that MCPG was reported to block induction of LTD (Haruta et al., 1994) and depotentiation (Hensch and Stryker, 1996) induced with low-frequency stimulation of visual cortex. These findings in visual cortex took on added significance with the further observation by Hensch and Stryker (1996) that MCPG infusion into the visual cortex in vivo fails to inhibit experience-dependent plasticity. These authors concluded, first, that MCPG-sensitive mGluRs, including those coupled to PI turnover, are not involved in ocular dominance plasticity. Second, because of the dissociation of the effect of MCPG on LTD and experience-dependent plasticity, Hensch and Stryker concluded that the mechanisms of LTD do not contribute to experience-dependent plasticity.

These provocative results prompted us to examine the effects of MCPG on NMDA receptor-dependent LTP and LTD in visual cortex (Kirkwood et al., 1993). We show here that MCPG has no effect on induction of either form of plasticity in visual cortex. Moreover, and perhaps of broader significance, we show that the absence of an effect of MCPG on plasticity cannot be taken as evidence excluding a role for mGluRs coupled to PI turnover. Although MCPG does competitively block actions of the mGluR agonist ACPD in visual cortex, it is virtually ineffective against specific metabotropic actions of glutamate, the endogenous ligand.

Parts of this paper have been presented and published previously (Huber et al., 1996).

\section{MATERIALS AND METHODS}

Materials. (+)-MCPG, ACPD, $(R, S)$-3,5-dihydroxyphenylglycine (DHPG), and 6-cyano-7-nitroquinoxaline-2,3-dione (CNQX) were purchased from Tocris Cookson (St. Louis, MO). MCPG, ACPD, and 2-hydroxy-saclofen were prepared as a $100-1000 \times$ stock in equimolar $\mathrm{NaOH}$ and were aliquoted and stored at $-20^{\circ} \mathrm{C}$. DHPG, bicuculline, and atropine were prepared as a $100 \times$ stock in $\mathrm{H}_{2} \mathrm{O}$ and were aliquoted and stored at $-20^{\circ} \mathrm{C}$. These stocks were diluted in artificial CSF (ACSF) to achieve their final concentrations. Most other chemicals were purchased from Sigma (St. Louis, MO); 2-myo- $\left[{ }^{3} \mathrm{H}\right]$ inositol $(10-25 \mathrm{Ci} / \mathrm{mmol})$ was purchased from DuPont NEN (Boston, MA).

Electrophysiology. Long-Evans rats (Charles River, Cambridge, MA) were anesthetized with the inhalation anesthetic methoxyflurane and decapitated soon after the disappearance of a tail withdrawal reflex. The brain was removed, dissected into blocks, and sliced (DSK Microslicer; Ted Pella) in ice-cold dissection buffer containing (in mM): sucrose, 212; $\mathrm{KCl}, 2.6 ; \mathrm{NaH}_{2} \mathrm{PO}_{4}, 1.25 ; \mathrm{NaHCO}_{3}, 26 ; \mathrm{MgCl}_{2}, 5 ; \mathrm{CaCl}_{2}, 0.5$; dextrose, 10; and kynurenic acid, 10 . Slices, $400 \mu \mathrm{m}$ thick, were allowed to recover for 1-2 hr at room temperature in ACSF containing (in $\mathrm{mM}$ ): $\mathrm{NaCl}, 124$; $\mathrm{KCl}, 5 ; \mathrm{NaH}_{2} \mathrm{PO}_{4}, 1.25 ; \mathrm{NaHCO}_{3}, 26 ; \mathrm{MgCl}_{2}, 1 ; \mathrm{CaCl}_{2}, 2$; and dextrose, 10. ACSF and dissection buffer were saturated in $95 \% \mathrm{O}_{2} / 5 \% \mathrm{CO}_{2}$. For recording, slices were placed in a submersion recording chamber, maintained at $30^{\circ} \mathrm{C}$, and perfused with ACSF at a rate of $2 \mathrm{ml} / \mathrm{min}$. In experiments designed to test drug effects on spike adaptation to depolarizing current injection, intracellular microelectrodes (80-120 M $\Omega$ ) were filled with $3 \mathrm{M}$ potassium acetate and $10 \mathrm{~mm} \mathrm{KCl}$, and regularspiking neurons (Connors and Gutnick, 1990) in layer II-III were impaled. To elicit action potentials and measure spike adaptation, we used a $1 \mathrm{sec}$ depolarizing current injection $(0.2-0.6 \mathrm{nA})$. In experiments designed to assess drug effects on synaptic plasticity, extracellular record- ing electrodes (1.0 M $\Omega$ ) were filled with ACSF and placed in layer II-III. Field potentials (FPs) were evoked with a stimulating electrode (concentric bipolar tungsten; Frederick Haer and Co.) placed either in the white matter or in the center of the cortical thickness histologically confirmed to correspond with layer IV and upper layer V. Changes in the amplitude of the maximum negative FP have been shown to correspond to changes in size of a monosynaptic current sink (Aizenman et al., 1996) and therefore were used to measure the magnitude of LTP and LTD. Recordings were made from both the monocular and binocular regions of rat area 17 (OC1). In neither this study nor in previous slice studies performed in this laboratory have we detected any systematic difference in the parameters measured from the monocular or binocular segments of area 17.

Stable baseline responses were collected every $15 \mathrm{sec}$ using a stimulation intensity yielding $50-60 \%$ of the maximal response. LTP was induced using $\theta$-burst stimulation (TBS), and LTD was induced using low-frequency stimulation (LFS). TBS consisted of 10 bursts at $5 \mathrm{~Hz}$, each burst containing four pulses at $100 \mathrm{~Hz}$, given four times at $10 \mathrm{sec}$ intervals. LFS consisted of 900 pulses at $1 \mathrm{~Hz}$. The FP group data were analyzed as follows: (1) the maximum negative FP amplitude data for each experiment were expressed as percentages of the preconditioning baseline average, (2) the time scale in each experiment was converted to time from the onset of conditioning, and (3) the time-matched, normalized data were averaged across experiments and expressed as the means \pm SEM. MCPG and control groups were compared using a $t$ test at the time point $30 \mathrm{~min}$ after cessation of TBS or LFS. A paired $t$ test was used to determine significance of the effects of ACPD wash-on (see Fig. $1 B$ ), of LFS in the depotentiation experiments (see Fig. 3), and of MCPG effects on spike adaptation (see Fig. 7).

Phosphoinositide turnover assays. Synaptoneurosomes were prepared from rat visual cortices, and PI turnover assays were performed as described (Dudek et al., 1989). Under our reaction conditions, PI turnover stimulated by glutamate $(200 \mu \mathrm{M})$ is linear for at least $2 \mathrm{hr}$. Each curve (see Fig. 4) represents an average \pm SEM of individual experiments performed in triplicate. $\mathrm{EC}_{50}$ values were obtained from best-fit sigmoidal dose-response curves generated using Graphpad Prism (Graph Pad, San Diego, CA). $K_{\mathrm{B}}$ values were determined according to the formula $\mathrm{EC}_{50 \mathrm{i}}=\mathrm{EC}_{50}\left(1+[I] / K_{\mathrm{B}}\right)$, where $\mathrm{EC}_{50 \mathrm{i}}$ is the $\mathrm{EC}_{50}$ determined in the presence of the inhibitor, and $[I]$ is the concentration of the inhibitor (Brabet et al., 1995).

\section{RESULTS}

\section{MCPG rapidly blocks ACPD activation of mGluRs but does not prevent LTP or LTD in visual cortical slices prepared from young adult (postnatal day 35-postnatal day 50 ) rats}

The first series of experiments was conducted using slices of visual cortex from young adult [postnatal day 35 (P35)-P50] rats. We first asked what inf usion time was required to reach a steadystate concentration of drug in the tissue. To determine this time and to confirm that MCPG was active under the conditions of our experiments, we investigated the ability of MCPG to block the effects of ACPD on synaptic responses evoked in layer III by layer IV stimulation (Fig. $1 A$ ). As reported previously for hippocampus (Baskys and Malenka, 1991; Selig et al., 1995), ACPD (10 $\mu \mathrm{M})$ reversibly attenuated synaptic transmission (Fig. $1 B$ ). The effect of ACPD was asymptotic after 10 min of infusion. Subsequent application of MCPG $(0.25 \mathrm{~mm})$ significantly reduced the ACPD-induced synaptic depression, and again, the effect of the drug was asymptotic after $10 \mathrm{~min}$ of infusion (Fig. 1B).

ACPD-induced synaptic depression is mediated presynaptically by a number of mGluRs, including some that are not coupled to PI turnover (Gereau and Conn, 1995a). To address the unlikely possibility that the pharmacokinetics of MCPG might be different for the subset of mGluRs coupled to PI turnover, we determined whether a 10 min preincubation with MCPG $(0.5 \mathrm{~mm})$ was sufficient to block the synaptic depression caused by $100 \mu \mathrm{M}$ DHPG. DHPG is a selective agonist at mGluRs coupled to PI turnover (Schoepp et al., 1994) and, like ACPD, causes a depression of 
A
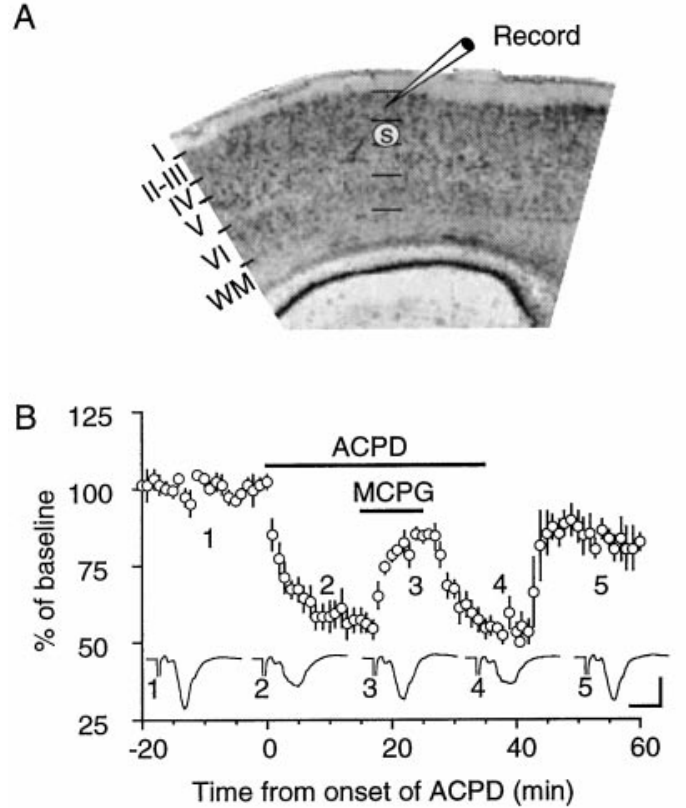

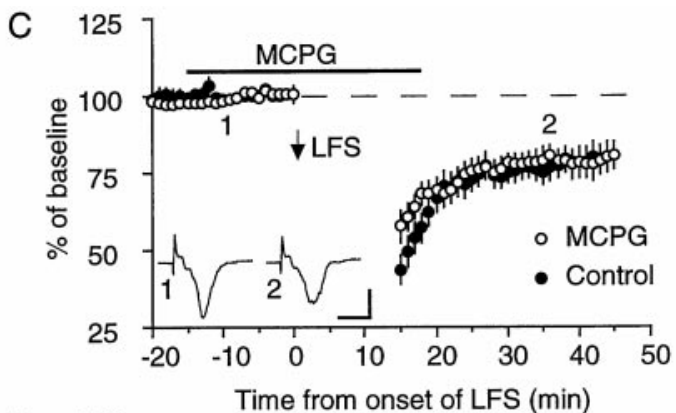

$\mathrm{D}$

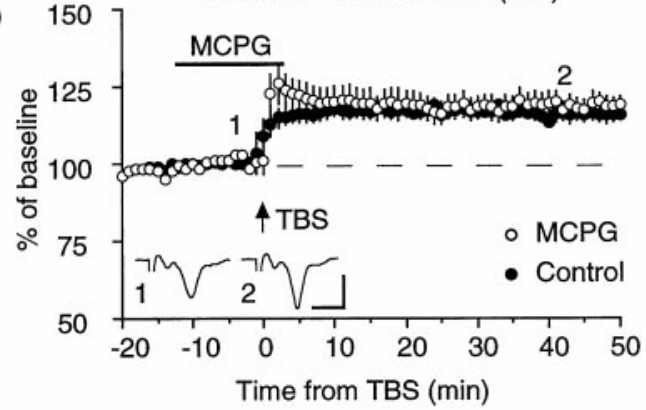

Figure 1. MCPG antagonizes the effects of ACPD on synaptic transmission but does not affect synaptic plasticity in visual cortical slices from young adult (P35P50) rats. $A$, Image of a Nisslstained section of rat visual cortex depicting placement of the stimulating electrode $(S)$ in layer IV and upper layer $\mathrm{V}$ and the extracellular recording electrode (Record) in layer III is shown. $W M$, White matter. $B$, Application of ACPD $(10 \mu \mathrm{M})$ reduced FP amplitudes ( $58 \pm 4 \%$ of baseline values); MCPG (0.25 mM; 10 min) significantly antagonized this ACPD-induced synaptic depression $(83 \pm 1 \%$ of baseline values; $n=4 ; p<0.01)$. Traces here and in subsequent figures are averages of four consecutive FPs taken at the times indicated by the numbers (1-5) on the graphs. Calibration: $1 \mathrm{mV}, 5$ msec. $C$, MCPG (0.25-1 mM) applied $15 \mathrm{~min}$ before and during LFS (1 Hz; 900 pulses) did not affect the magnitude of LTD. Control LTD magnitude was $78 \pm 2 \%$ of pre-LFS baseline $(n=8)$; MCPG LTD magnitude was $78 \pm 3 \%(n=7)$. Traces are taken at the times indicated (numbers 1 and 2) from one representative slice treated with MCPG ( $0.25 \mathrm{~mm})$. Calibration: $0.5 \mathrm{mV}, 5 \mathrm{msec} . D$, MCPG $(0.25-1.0 \mathrm{mM})$ applied $15 \mathrm{~min}$ before and during TBS did not affect the magnitude of LTP of FP amplitudes. Control LTP magnitude was $117 \pm 2 \%$ of pre-TBS baseline $(n=10)$; MCPG LTP magnitude was $118 \pm 4 \%(n=9)$. Traces are taken at the times indicated (numbers 1 and 2$)$ from one representative slice treated with MCPG $(0.25 \mathrm{mM})$. Calibration: $0.5 \mathrm{mV}, 5 \mathrm{msec}$.

synaptic transmission $(81 \pm 4 \%$ of control response amplitude; $n=6$ ). This effect was completely blocked when MCPG infusion was begun $10 \mathrm{~min}$ before DHPG application $(102 \pm 5 \% ; n=6$; $p<0.05$; data not shown). We also examined a purely postsynaptic consequence of mGluR activation (see below) and again found that MCPG was maximally effective within $10 \mathrm{~min}$ of infusion. These data confirm that under the conditions of our experiments, MCPG reaches an effective steady-state concentration 10 min after starting infusion into the recording chamber.

The design of our experiments examining MCPG effects on LTD and LTP induction was as follows. Infusion of MCPG was initiated once $>10$ min of stable baseline responses had been obtained. Fifteen minutes after beginning MCPG infusion, tetanic stimulation was delivered, LFS for induction of LTD and TBS for induction of LTP. The MCPG inf usion was discontinued 3-5 min after cessation of the tetanic stimulation. Data obtained from MCPG-treated slices were compared with those collected from interleaved, same-day control slices. Because inhibition of LTD was reported using 0.5 mM ( \pm )-MCPG (Haruta et al., 1994; Hensch and Stryker, 1996), we initially used the active form [(+)-MCPG] at $0.25 \mathrm{~mm}$, although identical results were obtained with concentrations as high as $1 \mathrm{~mm}$.

Our data on MCPG effects on LTD and LTP in slices of visual cortex from young adult rats are summarized in Figure 1, $C$ and D. MCPG (0.25-1.0 mM) had no effect on induction of either form of synaptic plasticity.

\section{MCPG does not prevent induction of LTP, LTD, or depotentiation in visual cortical slices prepared from P14-P29 rats}

The second series of experiments was conducted using slices of visual cortex from juvenile (P14-P29) rats, an age when glutamate-stimulated PI turnover is significantly greater than it is in adults (Dudek et al., 1989). This age range is also within the critical period for experience-dependent visual cortical plasticity in the rat (Fagiolini et al., 1994). Using MCPG reversal of ACPD-induced synaptic depression, we confirmed that MCPG was effective in slices from these animals and that steady-state effects were achieved in $\leq 10$ min of infusion ( $n=3$; data not shown).

Unlike LTP evoked using tetanic stimulation of layer IV, LTP evoked using white matter (WM) stimulation declines with increasing postnatal age and is well correlated with the reduction in experience-dependent plasticity and glutamate-stimulated PI turnover in visual cortex (Kato et al., 1991; Kirkwood et al., 1995). Therefore, in this series of experiments, we moved the stimulating electrode to the WM (Fig. $2 A$ ). Other than this change in the position of the stimulating electrode, the design of this series of LTP and LTD experiments was similar to that of the first series. The results are summarized in Figure 2. MCPG $(0.25-1.0 \mathrm{~mm})$ did not affect the induction of LTP or LTD in visual cortex of young rats using WM stimulation.

In a final series of plasticity experiments, the stimulating electrode was placed in layer IV of juvenile (P17-P28) visual cortex. LFS of layer IV can produce LTD of responses in layer III regardless of whether LTP has been induced previously. However, weakening of previously potentiated synapses may also result from deconsolidation of LTP, and this may involve mechanisms other than those used during LTD induction de novo (Bear and Abraham, 1996). The "depotentiation" of previously potentiated responses in visual cortex of young mice reportedly is blocked by MCPG (Hensch and Stryker, 1996). Therefore, we examined the effects of MCPG on LTD induction after previous establishment of LTP. Again, however, LFS produced significant LTD (depotentiation) in the presence of the drug $(0.5-1.0 \mathrm{~mm})$ that was not significantly different from that observed in control slices (Fig. 3). We conclude that under the conditions of our 

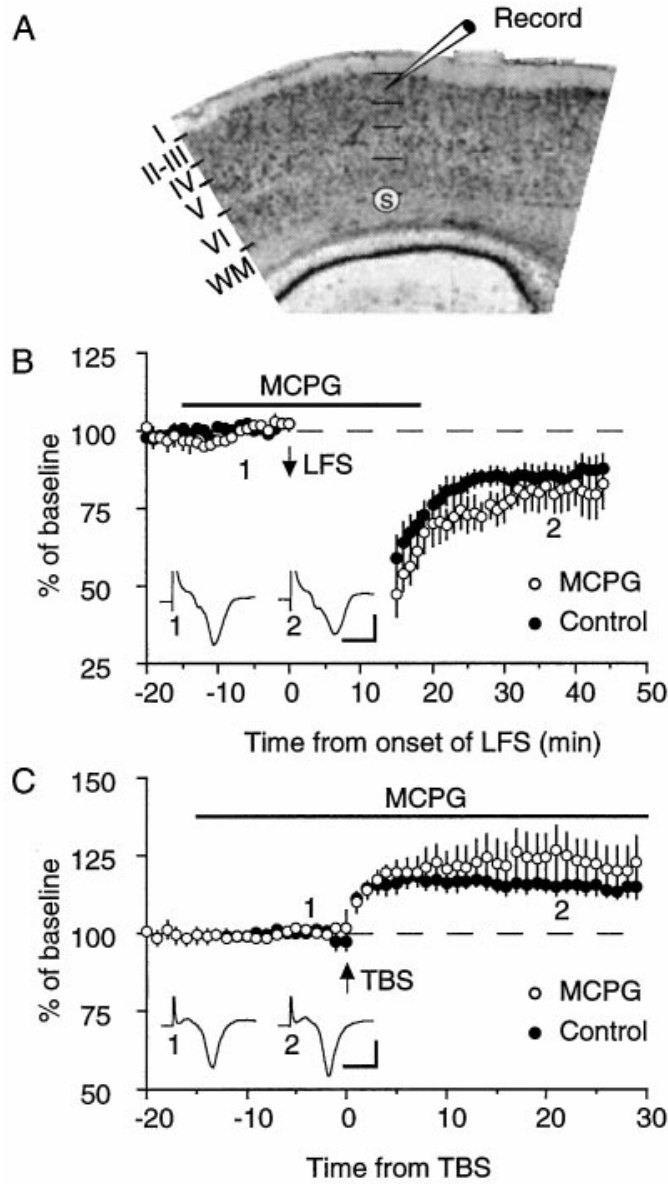

Figure 2. MCPG does not affect the induction of LTD or LTP in visual cortex of young (P14-P29) rats. $A$, Image of a Nissl-stained section of rat visual cortex depicting placement of the stimulating electrode $(S)$ at the border of white matter $(W M)$ and layer VI and the extracellular recording electrode (Record) in layer III. B, LTD of FP amplitudes evoked by LFS of WM in control ( $87 \pm 4 \%$ of pre-LFS baseline; $n=6)$ and MCPGtreated $(0.25-1.0 \mathrm{~mm} ; 85 \pm 4 \% ; n=6 ; p>0.7)$ slices. Traces were taken at the times indicated (numbers 1 and 2) from one representative slice treated with MCPG (1.0 mM). Calibration: $0.5 \mathrm{mV}, 5 \mathrm{msec}$. $C$, LTP of FP amplitudes evoked by TBS of WM in control $(115 \pm 4 \%$ of pre-TBS baseline; $n=8)$ and MCPG-treated (0.25-1.0 mM; $121 \pm 7 \% ; n=6 ; p>$ $0.3)$ slices. Note that the duration of MCPG treatment was extended in these experiments to $30 \mathrm{~min}$ post-TBS. Traces were taken at the times indicated (numbers 1 and 2) from one representative slice treated with MCPG (1.0 mM). Calibration, $0.5 \mathrm{mV}, 5 \mathrm{msec}$.

experiments, MCPG has no effect on LTP, LTD, or depotentiation in visual cortex during or after the critical period of experience-dependent plasticity.

\section{MCPG antagonizes ACPD-stimulated, but not glutamate-stimulated, PI turnover in visual cortical synaptoneurosomes}

Based on the effects of MCPG on LTP and LTD in our experiments, it is tempting to conclude that mGluR-mediated PI turnover does not play a role in visual cortical plasticity. However, this conclusion rests on the assumption that MCPG is an effective antagonist of glutamate-stimulated PI turnover in visual cortex. Although MCPG competitively antagonizes ACPD-stimulated PI turnover in cortical slices (Birse et al., 1993; Eaton et al., 1993) and in non-neuronal cell lines expressing mGluRs (Hayashi et al., 1994; Brabet et al., 1995), it has never been established that MCPG is effective against PI-turnover stimulated by the action of

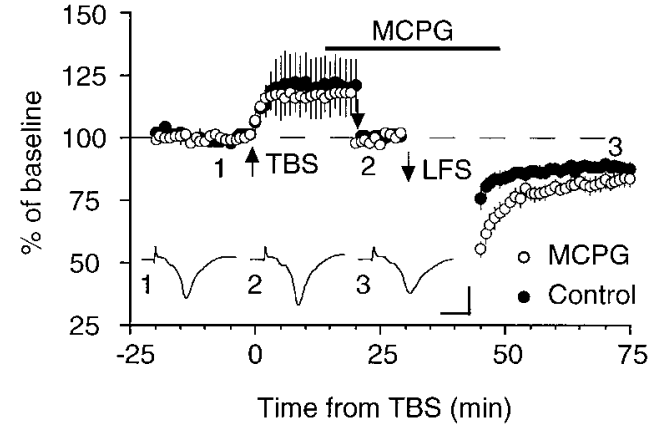

Figure 3. MCPG does not affect the induction of depotentiation in young (P17-P28) rats. See Figure $1 A$ for the stimulation-recording arrangement for these experiments. Thirty minutes after LTP was induced with TBS, significant depotentiation was obtained (open circles, $82 \pm 3 \%$ of pre-LFS baseline; $n=5 ; p<0.001$ ) using LFS in the presence of MCPG (0.5-1.0 mM). The magnitude of the depotentiation in MCPG was not significantly different from control ( filled circles, $88 \pm 3 \%$ of pre-LFS baseline; $n=5$ ). Response amplitudes after TBS were renormalized at the unlabeled downward arrow. Traces were taken at the times indicated (numbers 1-3) from one representative slice treated with MCPG (0.5 $\mathrm{mm})$. Calibration, $0.5 \mathrm{mV}, 5 \mathrm{msec}$.

glutamate at mGluRs in neocortex. Indeed, recent evidence from non-neuronal cells expressing mGluR clones indicates that MCPG is ineffective in blocking glutamate-stimulated PI turnover (Brabet et al., 1995). Therefore, we examined this question by studying the effects of MCPG on glutamate- and ACPDstimulated PI turnover in synaptoneurosomes prepared from the visual cortex of $\mathrm{P} 21-\mathrm{P} 28$ rats.

The rate of PI hydrolysis is determined in this assay by measuring the inositol monophosphate (IP1) that is generated in the continuous presence of agonist (Gusovsky and Daly, 1988). Under our assay conditions, IP1 accumulation increases linearly for up to $2 \mathrm{hr}$ of stimulation; therefore, we measured IP1 after $90 \mathrm{~min}$ of incubation in glutamate or ACPD in the presence or absence of MCPG. Previous work has shown that AMPA (10-1000 $\mu \mathrm{M})$ and NMDA $(10-1000 \mu \mathrm{M})$ fail to stimulate PI turnover in the cortical synaptoneurosome preparation and that glutamate-stimulated PI turnover is insensitive to blockers of NMDA and AMPA receptors, indicating that stimulation of PI turnover by glutamate is mediated solely by mGluRs (Dudek et al., 1989; Littman et al., 1992). Release of glutamate via activation of NMDA receptors (Montague et al., 1994) is not a complication because identical results are obtained in the presence or absence of the NMDA receptor antagonist D,L-2-amino-5-phosphonopentanoic acid (AP-5; $0.5 \mathrm{~mm}$ ) (Dudek et al., 1989); however, active glutamate uptake by neural and glial elements is known to lower the apparent potency of glutamate in the assay (e.g., Schousboe, 1981; Garthwaite, 1985; Littman and Robinson, 1994).

We confirmed that PI hydrolysis in visual cortex is stimulated by both ACPD and glutamate (Fig. $4 A, C$ ). Maximal stimulation was comparable $(293 \pm 21 \%$ of basal for ACPD; $262 \pm 11 \%$ of basal for glutamate; $n=3$ ); however, ACPD was more potent $\left(\mathrm{EC}_{50}, 25 \pm 2 \mu \mathrm{M}\right.$ for ACPD and $217 \pm 59 \mu \mathrm{M}$ for glutamate). Addition of $1 \mathrm{~mm}$ MCPG shifted the ACPD dose-response curve to the right $\left(K_{\mathrm{B}}, 276 \pm 84 \mu \mathrm{M}\right)$, consistent with competitive antagonism of ACPD at mGluRs (Fig. $4 A$ ). The $\mathrm{IC}_{50}$ of MCPG against half-maximal ACPD-stimulated PI turnover was $272 \mu \mathrm{M}$ (Fig. 4B). However, in striking contrast, MCPG was virtually without effect against glutamate-stimulated PI turnover $\left(K_{\mathrm{B}},>4\right.$ $\mathrm{mm} ; \mathrm{IC}_{50}, 3.8$ mM; Fig. $\left.4 C, D\right)$. 

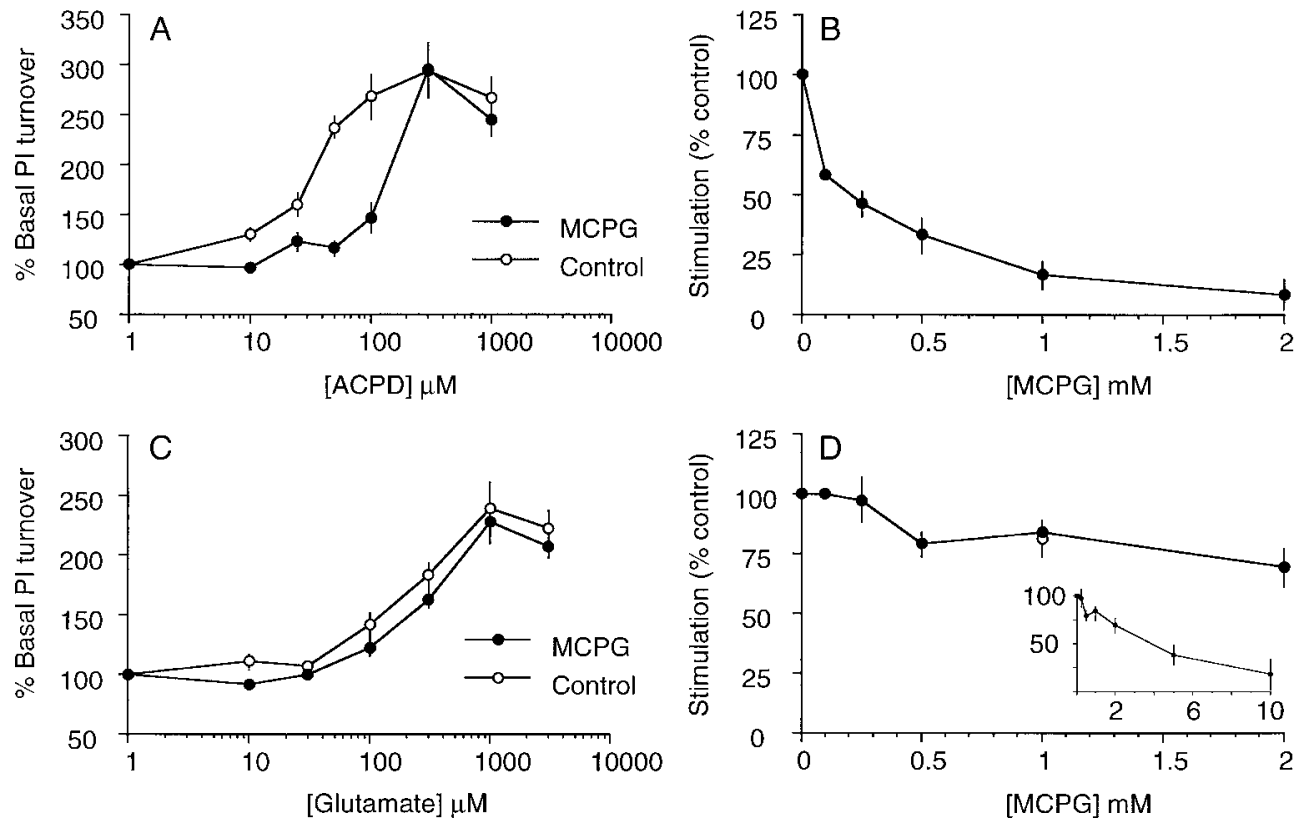

Figure 4. MCPG inhibits ACPDstimulated, but not glutamate-stimulated, PI hydrolysis in visual cortical synaptoneurosomes. A, ACPD dose-response curves expressed as the percent of basal PI turnover in the presence and absence of $1 \mathrm{~mm} \mathrm{MCPG}\left(K_{\mathrm{B}}, 276 \pm 84 \mu \mathrm{M} ; n=\right.$ 3). $B$, Effects of increasing concentrations of MCPG on PI turnover stimulated by $30 \mu \mathrm{M}$ ACPD $\left(\mathrm{IC}_{50}, 272 \mu \mathrm{M}\right.$; $n=3)$. C, Glutamate dose-response curves in the presence and absence of 1 $\mathrm{mm} \operatorname{MCPG}\left(K_{\mathrm{B}},>4 \mathrm{~mm} ; n=3\right)$. Kynurenate at $1 \mathrm{~mm}$ was also present in all of these experiments. A similar MCPG $K_{\mathrm{B}}$ value was obtained in experiments $(n=4$; data not shown) in which CNQX $(40 \mu \mathrm{M})$ and AP-5 $(200 \mu \mathrm{m})$ were also present. $D$, Effects of increasing MCPG concentrations on PI turnover stimulated by $200 \mu \mathrm{M}$ glutamate $\left(\mathrm{IC}_{50}, 3.8 \mathrm{mM} ; n=3\right)$. Addition of kynurenate (1 mM; open circle) did not affect the magnitude of PI turnover stimulated by glutamate $(1 \mathrm{~mm})$ in the presence or absence of MCPG (1 mM; $n=3$ ). Inset, Increasing the concentration of MCPG to $10 \mathrm{~mm}$ suppressed glutamate-stimulated PI turnover; however, this highconcentration also partially inhibited carbachol-stimulated PI turnover (data not shown).

Two lines of evidence confirm that the different effects of MCPG against ACPD- and glutamate-stimulated PI turnover are not caused by glutamate activation of ionotropic receptors. First, the broad-spectrum ionotropic glutamate receptor antagonist kynurenate $(1 \mathrm{mM})$ did not affect the magnitude of glutamatestimulated PI turnover in the presence or the absence of MCPG (Fig. 4C,D). Second, MCPG was similarly ineffective against glutamate-stimulated PI turnover in the presence of high affinity ionotropic glutamate receptor antagonists CNQX $(40 \mu \mathrm{M})$ and AP-5 $(200 \mu \mathrm{M})$ in the assay $(n=4$; data not shown). Thus, the MCPG-insensitive PI turnover that is stimulated by exogenous glutamate is not an indirect consequence of tissue depolarization via ionotropic receptor activation. Rather, it seems that glutamate activates mGluRs in visual cortex that are insensitive to MCPG.

\section{MCPG antagonizes ACPD-stimulated, but not glutamate-stimulated, changes in spike adaptation in layer III neurons}

Our biochemical results demonstrate that MCPG is ineffective as an antagonist of glutamate action at mGluRs coupled to PI turnover. However, the conditions of the biochemical assay (prolonged agonist treatments in synaptoneurosomes) might be biased against detecting more subtle physiological effects of MCPG against glutamate stimulation of PI-coupled mGluRs. Furthermore, because LTD and LTP induction occurs postsynaptically, it is important to determine the efficacy of MCPG against postsynaptic mGluRs. Therefore, we used a physiological assay of postsynaptic PI-coupled mGluR function in slices.

In pyramidal neurons, activation of PI-coupled mGluRs has effects on several $\mathrm{K}^{+}$conductances that can modulate the excitability of these neurons. Activation of postsynaptic PI-coupled mGluRs has been shown to depolarize cells by decreasing a $\mathrm{K}^{+}$ leak conductance and to reduce the afterhyperpolarization that follows a burst of action potentials by decreasing a $\mathrm{Ca}^{2+}$. activated $\mathrm{K}^{+}$conductance (Charpak et al., 1990; Gereau and Conn, 1995b). Modulation of these currents functions to decrease spike adaptation and increase the excitability of neurons. There- fore, we used spike adaptation as a measure of postsynaptic mGluR activation to assay the effectiveness of MCPG against ACPD and glutamate.

Intracellular recordings of regular spiking layer II-III cells were obtained (average resting $V_{\mathrm{m}},-76 \pm 1 \mathrm{mV}$; range, -70 to $-82 \mathrm{mV}$ ), and spike adaptation was measured by injecting a $1 \mathrm{sec}$ depolarizing current pulse (0.2-0.6 nA) adjusted to elicit 1-2 spikes under control conditions (Fig. 5). To ensure that we were measuring a mGluR-mediated response to ACPD or glutamate, we performed all experiments in the presence of ionotropic glutamate receptor antagonists (20 $\mu \mathrm{M}$ CNQX and $200 \mu \mathrm{M}$ AP-5), GABA receptor antagonists $(1 \mu \mathrm{M}$ bicuculline methiodide and $200 \mu \mathrm{M}$ 2-hydroxy-saclofen), and a muscarinic acetylcholine receptor antagonist (1 $\mu \mathrm{M}$ atropine). ACPD (30 $\mu \mathrm{M})$ induced a small depolarization $(3 \pm 1 \mathrm{mV} ; n=4)$ and a robust decrease in spike adaptation, measured as an increase in the number of spikes that occurred during the $1 \mathrm{sec}$ depolarizing current injection (e.g., Fig. 5; filled circles). A $10 \mathrm{~min}$ application of MCPG (1 mM) reversed the effect of ACPD on spike adaptation, and after MCPG washout, the ACPD effect returned. In four cells tested, ACPD increased the number of spikes during the $1 \mathrm{sec}$ depolarizing pulse to $11 \pm 3$, and MCPG significantly reduced this to $5 \pm$ 3 spikes/sec $(p<0.05$; see Fig. 7$)$.

We initially planned to use agonist concentrations that yielded half-maximal stimulation of PI turnover to facilitate a direct comparison of the biochemical and physiological assays. However, although we observed a large effect with $30 \mu \mathrm{M}$ ACPD, the effect of $200 \mu \mathrm{M}$ glutamate on spike adaptation was either small or nonexistent. Therefore, we increased the glutamate concentration until we obtained a response that was similar in magnitude to that observed with $30 \mu \mathrm{M}$ ACPD. The requirement for a higher glutamate concentration is likely because of the greater glutamate uptake in slices (Schousboe, 1981). We found that $0.5 \mathrm{~mm}$ glutamate also consistently caused a reduction in spike adaptation (e.g., Fig. 5, open circles) accompanied by a small change in membrane potential $(4 \pm 2 \mathrm{mV} ; n=7)$. However, MCPG (1 mM) 


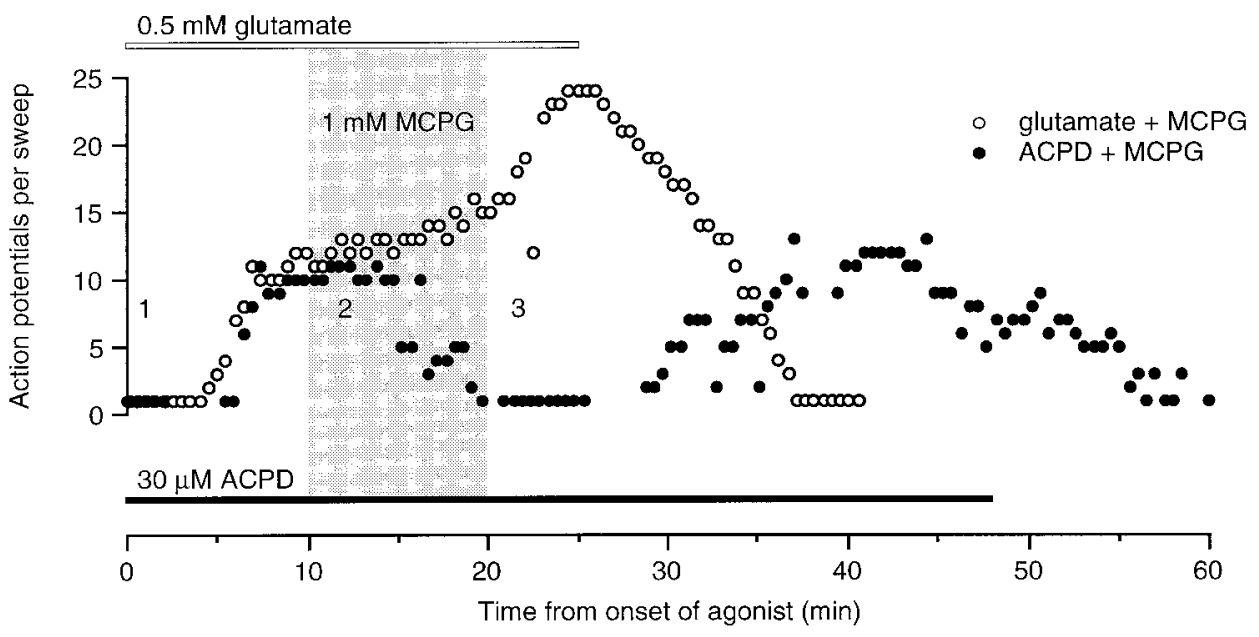

Figure 5. Differential effect of MCPG on the inhibition of spike adaptation in layer II-III neurons by glutamate and ACPD. Superimposed records of two similar experiments in which MCPG was applied $10 \mathrm{~min}$ after inducing a change in spike adaptation with either glutamate (open circles) or ACPD (filled circles). The data plotted in the graph are the number of spikes resulting from a $1 \mathrm{sec}$ depolarizing current injection $(0.3 \mathrm{nA})$ through an intracellular recording electrode. All intracellular recordings were in the presence of CNQX $(20 \mu \mathrm{M})$, AP-5 $(200 \mu \mathrm{M})$, bicuculline methiodide $(1 \mu \mathrm{M})$, 2-hydroxysaclofen $(200 \mu \mathrm{M})$, and atropine $(1 \mu \mathrm{M})$. Representative waveforms of intracellular recordings are shown, taken at times indicated by the numbers (1-3) in the graph. Spikes have been truncated. Calibration: the absolute membrane potential and time $(0.5 \mathrm{sec})$. The drugs reach the slice chamber 5 min after starting their infusion into the ACSF line, and their effects generally stabilize after an additional $5 \mathrm{~min}$. Although a $10 \mathrm{~min}$ exposure to MCPG reverses the ACPD-induced inhibition of spike adaptation, it has an additive effect on the glutamate-induced inhibition.

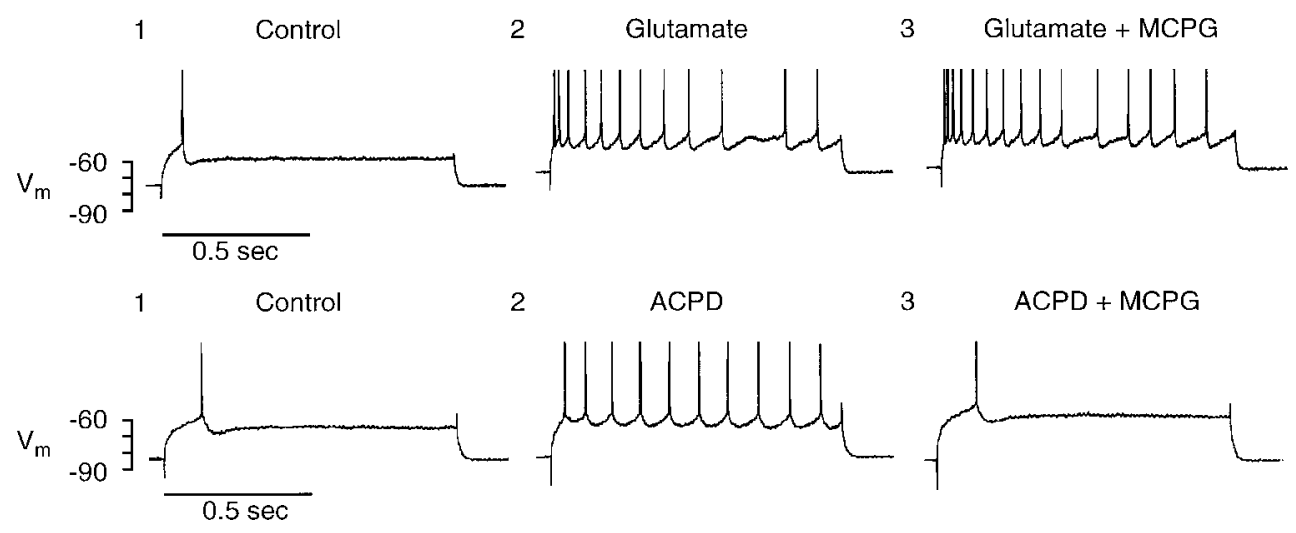

failed to attenuate the glutamate-stimulated reduction in spike adaptation. In fact, the number of spikes during the depolarizing pulse was usually increased further by MCPG. This increase in excitability was observed both when MCPG was applied after glutamate ( $n=7$ cells; e.g., Fig. 5) and when MCPG was applied to cells without any previous exposure to exogenous glutamate ( $n=4$ cells; e.g., Fig. 6). The effects of ACPD, glutamate, and MCPG on spike adaptation are summarized in Figure 7.

The mechanism of the effect of MCPG on spike adaptation is unknown. However, this may explain why MCPG failed to block completely the ACPD-induced reduction of spike adaptation in most cells (Fig. 7). Regardless of the mechanism, MCPG clearly does not block the action of glutamate at postsynaptic PI-coupled mGluRs. These findings confirm the conclusion of our biochemical study: MCPG has very different effects on ACPD and glutamate activation of the mGluRs coupled to PI turnover. MCPG is virtually without effect against activation of PI-coupled mGluRs by glutamate, the endogenous ligand.

\section{DISCUSSION}

The major findings of this study may be summarized as follows. (1) At concentrations up to $1 \mathrm{~mm}$, the active isomer of MCPG has no significant effect on the induction of LTP, LTD, or depotentiation in the visual cortex, under experimental conditions in which these forms of synaptic plasticity have been shown to be sensitive to blockers of NMDA receptors (Kirkwood and Bear, 1994a,b). (2) MCPG has differential effects on PI turnover stimulated at mGluRs by the synthetic agonist ACPD and the natural ligand glutamate. Whereas MCPG competitively antagonizes
ACPD-induced stimulation, it is virtually without effect against glutamate-induced stimulation. (3) MCPG has differential effects on the mGluR-mediated changes in spike adaptation caused by ACPD and glutamate. Although MCPG partially reduces the effect of ACPD, it is without effect against glutamate. Taken together, the results indicate that MCPG is not a useful antagonist of glutamate actions at PI-coupled mGluRs in the cerebral cortex. Thus, the lack of effect of MCPG against synaptic plasticity cannot be taken as evidence that PI-coupled mGluRs are not involved in synaptic plasticity. In addition, the results suggest that one cannot automatically accept evidence that MCPG antagonizes ACPD actions as proof that MCPG is effective against synaptic activation of all types of mGluR.

\section{Differential effects of MCPG against ACPD and glutamate stimulation of PI turnover in visual cortex}

Our findings that MCPG is more effective in blocking ACPDthan glutamate-stimulated PI turnover are consistent with recent studies of the effects of MCPG on mGluRs expressed in nonneuronal cells (Brabet et al., 1995; Joly et al., 1995). Glutamatestimulated PI turnover is mediated by several mGluR subtypes, collectively called group 1 mGluRs, of which two have been cloned, mGluR1 and mGluR5 (Suzdak et al., 1994; Pin and Bockaert, 1995). MCPG was found to be very effective against ACPD-stimulated PI turnover via both mGluR1 $\left(K_{\mathrm{B}}, 123 \mu \mathrm{M}\right)$ and mGluR5 $\left(K_{\mathrm{B}}, 153 \mu \mathrm{M}\right)$. However, MCPG was less potent against glutamate-stimulated PI turnover in cells expressing mGluR1 $\left(K_{\mathrm{B}}, 542 \mu \mathrm{M}\right)$ and was virtually ineffective in mGluR5expressing cells $\left(K_{\mathrm{B}},>2 \mathrm{~mm}\right)$. From these data it has been 

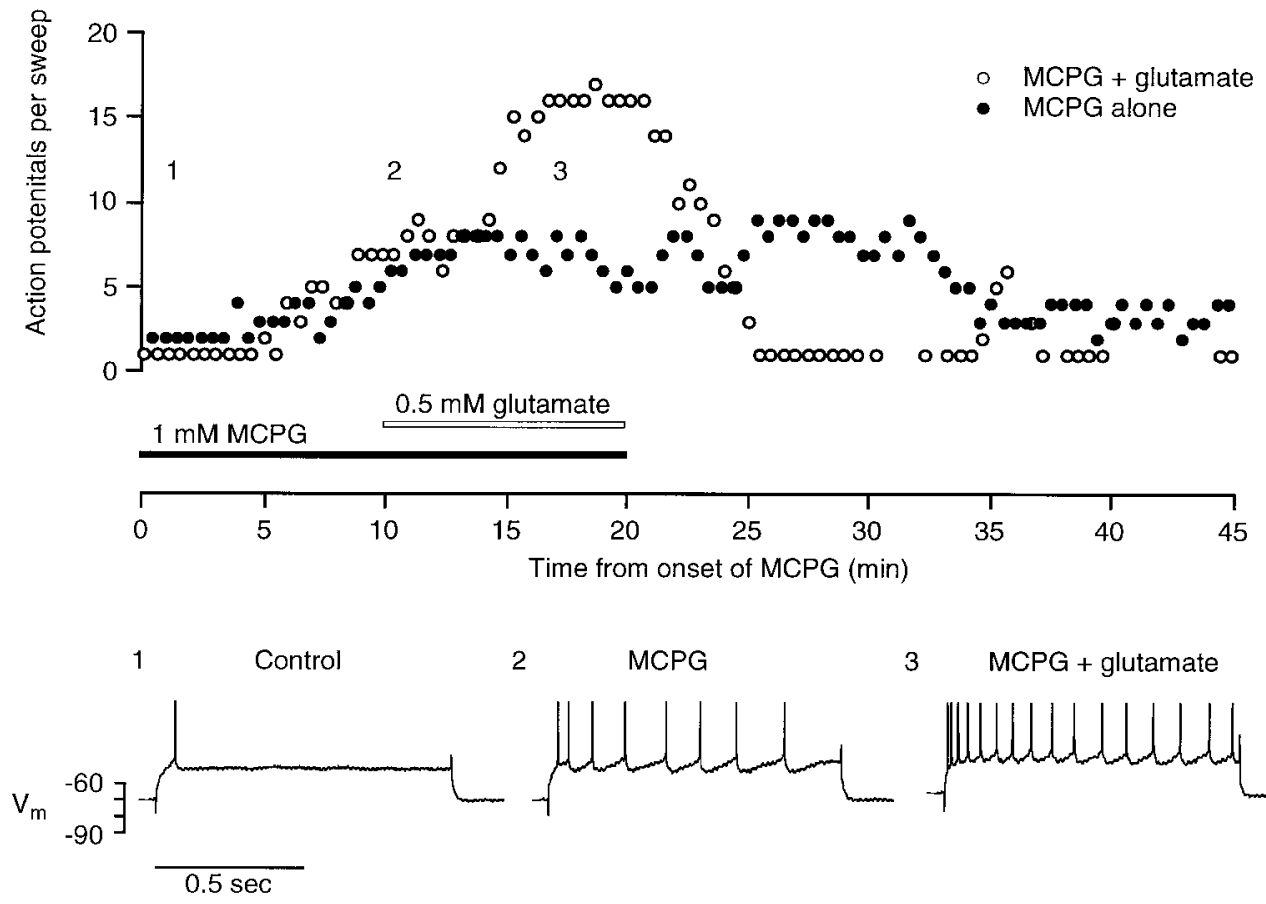

$2 \quad \mathrm{MCPG}$

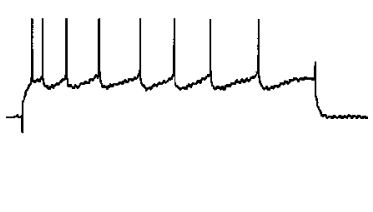

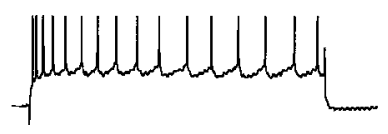

Figure 6. MCPG alone inhibits spike adaptation in layer II-III neurons. Superimposed records of two similar experiments in which MCPG (1 mM) was applied for $20 \mathrm{~min}$. Filled circles are from an experiment in which only MCPG was applied; open circles are from an experiment in which glutamate was applied $10 \mathrm{~min}$ after starting the MCPG infusion. The data plotted in the graph are the number of spikes resulting from a $1 \mathrm{sec}$ depolarizing current injection through an intracellular recording electrode. All intracellular recordings were in the presence of CNQX (20 $\mu \mathrm{M})$, AP-5 (200 $\mu \mathrm{M})$, bicuculline methiodide $(1 \mu \mathrm{M}), 2$-hydroxysaclofen $(200 \mu \mathrm{M})$ and atropine $(1 \mu \mathrm{M})$. Representative waveforms of intracellular recordings are shown, taken at times indicated by the numbers $(1-3)$ in the graph from the experiment in which glutamate was also applied (open circles). Spikes have been truncated. Calibration: see Fig. 5 legend. The absolute membrane potential and time $(0.5 \mathrm{sec})$. suggested that ACPD and glutamate act at distinct sites on mGluR5, and MCPG blocks only the ACPD-binding site (Brabet et al., 1995). Interestingly, MCPG is also without effect on glutamate-stimulated PI turnover in hippocampus (Littman and Robinson, 1994) that, like the neocortex, has a high level of mGluR5 expression (Abe et al., 1992; Testa et al., 1994; Romano et al., 1995). Taken together, the data suggest that mGluR5, or another yet-to-be-cloned MCPG-insensitive mGluR (Chang et al., 1994), mediates most of the glutamate-stimulated PI turnover in visual cortex and hippocampus.

One study performed in oocytes expressing mGluR5 found that $0.5 \mathrm{~mm}$ MCPG could reduce the effects of $10 \mu \mathrm{M}$ glutamate by $50 \%$ (Saugstad et al., 1995). Unfortunately, a $K_{\mathrm{B}}$ value was not determined in this study. Generating a $K_{\mathrm{B}}$ using a range of agonist concentrations is necessary to compare the relative effectiveness of MCPG against the actions of ACPD and glutamate within and across preparations. Unlike the oocyte preparation, in the synaptoneurosome preparation, there are significant glutamate uptake mechanisms that prevent us from measuring PI turnover at low glutamate concentrations. However, when we also used a 50:1 ratio of MCPG $(10 \mathrm{~mm})$ to glutamate $(200 \mu \mathrm{M})$, we were able to substantially inhibit glutamate-stimulated PI turnover (Fig. 4D; inset). Glutamate $(200 \mu \mathrm{M})$ approximates the concentration that has been estimated to occur in the synaptic cleft during synaptic transmission, which is believed to peak at over $1 \mathrm{~mm}$ (Clements et al., 1992). The results of Saugsted et al. (1995) are therefore consistent with ours and indicate that MCPG is a very weak antagonist of glutamate at mGluR5. It is not practical to use $10 \mathrm{~mm}$ MCPG in physiological experiments because of nonspecific effects.

\section{Differential effects of MCPG against ACPD and glutamate inhibition of spike adaptation in visual cortex}

ACPD $(30 \mu \mathrm{M})$, acting at postsynaptic mGluRs (most likely mGluR5), slightly depolarized layer III neurons and decreased spike adaptation in response to a steady depolarizing pulse. This

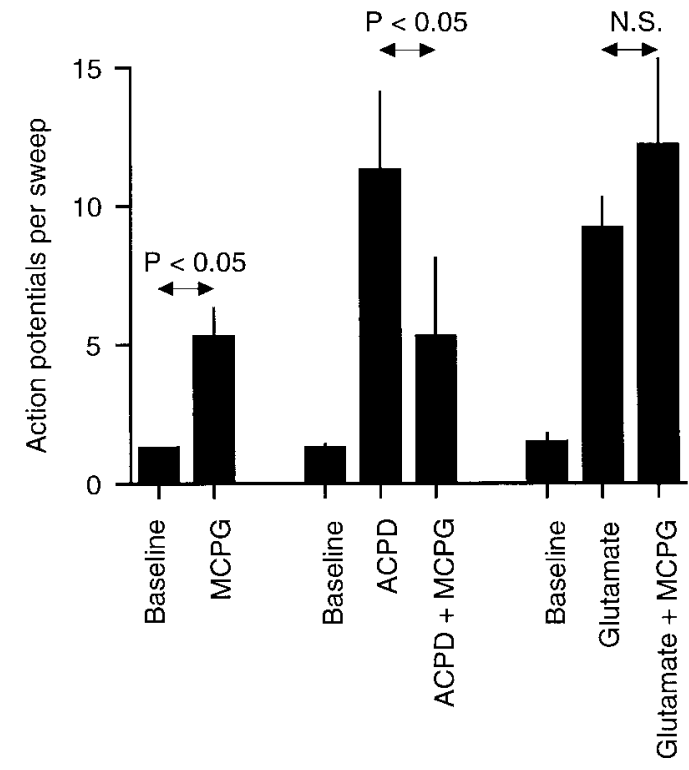

Figure 7. Average effects of MCPG, ACPD, and glutamate on spike adaptation in layer III neurons. MCPG (1 mM) alone increased the number of spikes per depolarizing pulse from a baseline value of $1.2 \pm 0.1$ to $5.3 \pm 1$ ( $n=4$; significant at $p<0.05$ using paired $t$ test). ACPD (30 $\mu \mathrm{M})$ increased the number of spikes per sweep from a baseline value of $1.2 \pm 0.1$ to $11.3 \pm 2.8(n=4)$. Application of $1 \mathrm{~mm} \mathrm{MCPG}$ significantly reduced the ACPD effect to $5.3 \pm 2.7$ spikes $(p<0.05$, paired $t$ test). Glutamate $(0.5 \mathrm{~mm})$ increased the number of spikes per sweep from a baseline value of $1.5 \pm 0.3$ to $9.2 \pm 1.1(n=7)$. Application of $1 \mathrm{~mm}$ MCPG did not inhibit the glutamate effect but rather tended to add to it (12.2 \pm 3.1 spikes per sweep).

effect of ACPD was reversibly inhibited by MCPG (1 mM). Glutamate $(0.5 \mathrm{~mm})$ also decreased spike adaptation, but this effect was insensitive to MCPG. We believe the glutamate effect is mediated via mGluRs, because the ionotropic AMPA and NMDA receptors were blocked with CNQX and AP-5, respec- 
tively. Glutamate did slightly depolarize the cells $(4 \pm 2 \mathrm{mV})$, but this was not significantly different from the effect of ACPD (3 \pm $1 \mathrm{mV})$. In addition, the concentrations of CNQX $(20 \mu \mathrm{M})$ and AP-5 $(200 \mu \mathrm{M})$ used in these experiments were double what was required to block completely the evoked synaptic EPSP, whereas the concentration of glutamate used $(0.5 \mathrm{~mm})$ was half of what has been estimated to occur in the synaptic cleft during normal synaptic transmission ( $\geq 1 \mathrm{~mm}$ ) (Clements et al., 1992). Therefore, we interpret the spike adaptation data as confirmation of the results of the PI turnover assay, that MCPG has very different effects against activation of PI-coupled mGluRs by ACPD and glutamate.

An unexpected observation was that MCPG alone induces significant changes in spike adaptation (Figs. 6,7). This effect may be attributable to the fact that MCPG is an effective antagonist of presynaptic group 2 and 3 mGluRs (Pin and Bockaert, 1995; Scanziani et al., 1997). These presynaptic mGluRs act as autoreceptors, may be activated with basal glutamate levels, and function to inhibit any further spontaneous glutamate release. Blockade of presynaptic mGluRs by MCPG may relieve this autoinhibition and indirectly increase spontaneous glutamate release. The increase in tissue glutamate levels may then activate postsynaptic group $1 \mathrm{mGluRs}$ at which MCPG has a low affinity. Although we were not able to detect any stimulatory effect of MCPG on PI turnover in the synaptoneurosomes, there may be less spontaneous glutamate release in that preparation. Alternatively, it is possible that there is stimulation by MCPG that is below our detection threshold.

\section{MCPG, mGluRs, LTP, and LTD}

Our results from both the PI turnover assay and spike adaptation experiments indicate that MCPG is ineffective against the actions of glutamate at the PI-linked mGluRs in the cerebral cortex. Because of this, perhaps it is not surprising that MCPG also has no effect (at concentrations up to $1 \mathrm{~mm}$ ) on induction of LTD or LTP in visual cortex of young or mature rats. Our data on visual cortex are also in agreement with several studies of MCPG effects on LTP and LTD in the CA1 region of the hippocampus (Chinestra et al., 1993; Manzoni et al., 1994; Selig et al., 1995; Thomas and O'Dell, 1995). However, our findings are at odds with other reports that MCPG blocks LFS-induced LTD in visual cortex (Haruta et al., 1994; Hensch and Stryker, 1996) and CA1 (Bashir and Collingridge, 1994; Bolshakov and Siegelbaum, 1994). We do not know what the critical difference is but note that under conditions in which MCPG blocks LTD in CA1, NMDA receptor antagonists do not (Bashir and Collingridge, 1994; Bolshakov and Siegelbaum, 1994; Oliet et al., 1997). Very recently it was reported that LFS can induce a presynaptic, NMDA receptorindependent form of LTD in the CA3 region of the hippocampus (Kobayashi et al., 1996; Yokoi et al., 1996). This form of LTD is attenuated by MCPG and by genetic ablation of mGluR2. It is possible that a presynaptic, MCPG-sensitive form of LTD coexists with a postsynaptic, NMDA receptor-dependent form of LTD in visual cortex and CA1 (Oliet et al., 1997). Under our experimental conditions, both LTP and LTD are blocked by NMDA receptor antagonists in visual cortex and CA1 (Kirkwood et al., 1993). Whatever the explanation, our data show that MCPG is not blocking a mechanism that is fundamental to induction of at least one form of LTD in the visual cortex.

\section{MCPG, mGluRs, and visual cortical plasticity}

Recently, Hensch and Stryker (1996) reported experiments in which MCPG was infused directly into the visual cortex while animals were monocularly deprived of vision. The aim of the study was to test the hypothesis that glutamate-stimulated PI turnover plays a central role in ocular dominance plasticity during early postnatal development (Dudek and Bear, 1989). If diff usion is taken into account, the concentration of MCPG in the extracellular space of the cortex examined would be expected to range from 0.5 to $1 \mathrm{~mm}$ (Bear et al., 1990). As a control for the effectiveness of the drug treatment, the authors showed that ionophoretic application of ACPD was much less effective in evoking action potentials in neurons recorded in the MCPGtreated cortex as compared with cortex infused only with vehicle solution. Nonetheless, MCPG treatment was found to have no significant effect on ocular dominance plasticity. From these data, the authors concluded that mGluR-mediated PI turnover does not contribute significantly to the activity-dependent refinement of connections in primary visual cortex.

The general argument could be made that such a strong conclusion should not be based on the effect of a single pharmacological reagent, and our data provide a clear demonstration of why such an objection is justified. MCPG is virtually ineffective against glutamate-stimulated PI turnover in visual neocortex. The ACPD ionophoresis controls used by Hensch and Stryker yielded a misleading conclusion because MCPG is at least 10 times more effective against ACPD actions at PI-coupled mGluRs in visual cortex than it is against glutamate actions.

It is still unclear whether mGluRs play a special role in visual cortical plasticity, as has been proposed (Dudek and Bear, 1989; Reid et al., 1996). However, it is clear that the absence of an effect of MCPG on synaptic plasticity in visual cortex (Hensch and Stryker, 1996) cannot be taken as evidence that PI-coupled mGluRs are not involved in synaptic plasticity. More potent and thoroughly tested mGluR antagonists are needed to conclusively determine whether mGluRs regulate visual cortical plasticity during development.

\section{REFERENCES}

Abe T, Sugihara H, Nawa H, Shigemoto R, Mizuno N, Nakanishi S (1992) Molecular characterization of a novel metabotropic glutamate receptor mGluR5 coupled to inositol phosphate/ $\mathrm{Ca}^{2+}$ signal transduction. J Biol Chem 267:13361-13368.

Aizenman CD, Kirkwood A, Bear MF (1996) Current source density analysis of evoked responses in visual cortex in vitro: implications for the regulation of long-term potentiation. Cereb Cortex 16:751-758.

Bashir, ZI, Bortolotto ZA, Davies CH, Berretta N, Irving AJ, Seal AJ, Henley JM, Jane DS, Watkins JC, Collingridge GL (1993) Induction of LTP in the hippocampus needs synaptic activation of glutamate metabotropic receptors. Nature 363:347-350.

Bashir ZI, Collingridge GL (1994) An investigation of depotentiation of long-term potentiation in the CA1 region of the hippocampus. Exp Brain Res 100:437-443.

Baskys A, Malenka RC (1991) Agonists at metabotropic glutamate receptors presynaptically inhibit EPSCs in neonatal rat hippocampus. J Physiol (Lond) 444:687-701.

Bear MF, Abraham WC (1996) Long-term depression in hippocampus. Annu Rev Neurosci 19:437-462.

Bear MF, Dudek SM (1991) Stimulation of phosphoinositide turnover by excitatory amino acids: pharmacology, development, and role in visual cortical plasticity. Ann NY Acad Sci 627:42-56.

Bear MF, Malenka RC (1994) Synaptic plasticity: LTP and LTD. Curr Opin Neurobiol 4:389-399.

Bear MF, Kleinschmidt A, Gu Q, Singer W (1990) Disruption of experience-dependent synaptic modifications in striate cortex by infusion of an NMDA receptor antagonist. J Neurosci 10:909-925.

Berridge MJ (1984) Inositol trisphosphate and diacylglycerol as second messengers. Biochem J 220:345-360.

Birse EF, Eaton SA, Jane DE, Jones PL, Porter RH, Pook PC-K, Sunter DC, Udvarhelyi PM, Wharton B, Roberts PJ, Salt TE, Watkins JC 
(1993) Phenylglycine derivatives as new pharmacological tools for investigating the role of metabotropic glutamate receptors in the central nervous system. Neuroscience 52:481-488.

Bolshakov VY, Siegelbaum SA (1994) Postsynaptic induction and presynaptic expression of hippocampal long-term depression. Science 264:1148-1152.

Bortolotto ZA, Bashir ZI, Davies CH, Collingridge GL (1994) A molecular switch activated by metabotropic glutamate receptors regulates induction of long-term potentiation. Nature 368:740-743.

Brabet I, Mary S, Bockaert J, Pin J-P (1995) Phenylglycine derivatives discriminate between mGluR1- and mGluR5-mediated responses. Neuropharmacology 34:895-903.

Castro-Alamancos MA, Donoghue JP, Connors BW (1995) Different forms of synaptic plasticity in somatosensory and motor areas of the neocortex. J Neurosci 15:5324-5333.

Chang DS, Winder DG, Conn PJ (1994) 4-Bromohomoibotenic acid selectively activates $\alpha$-1-aminocyclopentane- $1 S, 3 R$-dicarboxylic acidinsensitive metabotropic glutamate receptor coupled to phosphoinositide hydrolysis in rat cortical slices. J Neurochem 63:133-139.

Charpak S, Gahwiler BH, Do KQ, Knopfel T (1990) Potassium conductances in hippocampal neurons blocked by excitatory amino-acid transmitters. Nature 347:765-767.

Chen WR, Lee S, Kato K, Spencer DD, Shepherd GM, Williamson A (1996) Long-term modifications of synaptic efficacy in the human inferior and middle temporal cortex. Proc Natl Acad Sci USA 93:8011-8015.

Chinestra P, Aniksztejn L, Diabira D, Ben-Ari Y (1993) (RS)- $\alpha$-Methyl4-carboxyphenylglycine neither prevents induction of LTP nor antagonizes metabotropic glutamate receptors in CA1 hippocampal neurons. J Neurophysiol 70:2684-2689.

Clements JD, Lester RAJ, Tong G, Jahr CE, Westbrook GL (1992) The time course of glutamate in the synaptic cleft. Science 258:1498-1501.

Connors BW, Gutnick MJ (1990) Intrinsic firing patterns of diverse neocortical neurons. Trends Neurosci 13:99-104.

Dudek SM, Bear MF (1989) A biochemical correlate of the critical period for synaptic modification in the visual cortex. Science 246:673-675.

Dudek SM, Friedlander MJ (1996) Developmental down-regulation of LTD in cortical layer IV and its independence of modulation by inhibition. Neuron 16:1-20.

Dudek SM, Bowen WD, Bear MF (1989) Postnatal changes in glutamate stimulated phosphoinositide turnover in rat neocortical synaptoneurosomes. Dev Brain Res 47:123-128.

Eaton SA, Jane DE, Jones PLSJ, Porter RHP, Pook PC-K, Sunter DC, Udvarhelyi PM, Roberts PJ, Salt TE, Watkins JC (1993) Competitive antagonism at metabotropic glutamate receptors by $(S)-4$ carboxyphenylglycine and $(R S)$ - $\alpha$-methyl-4-carboxyphenylglycine. Eur J Pharmacol 244:195-197.

Fagiolini M, Pizzorusso T, Berardi N, Domenici L, Maffei L (1994) Functional postnatal development of the rat primary visual cortex and the role of visual experience: dark rearing and monocular deprivation. Vision Res 34:709-720.

Garthwaite J (1985) Cellular uptake disguises action of L-glutamate on $N$-methyl-D-aspartate receptors. Br J Pharmacol 85:297-307.

Gereau R, Conn PJ (1995a) Multiple presynaptic metabotropic glutamate receptors modulate excitatory and inhibitory synaptic transmission in hippocampal area CA1. J Neurosci 15:6879-6889.

Gereau R, Conn PJ (1995b) Roles of specific metabotropic glutamate receptor subtypes in regulation of hippocampal CA1 pyramidal cell excitability. J Neurophysiol 74:122-129.

Gusovsky F, Daly JW (1988) Formation of inositol phosphates in synaptoneurosomes of guinea pig brain: stimulatory effects of receptor agonists, sodium channel agents and sodium and calcium ionophores. Neuropharmacology 27:95-105.

Haruta H, Kamishita T, Hicks TP, Takahashi MP, Tsumoto T (1994) Induction of LTD but not LTP through metabotropic glutamate receptors in visual cortex. NeuroReport 5:1829-1832.

Hayashi Y, Sekiyama N, Nakanishi S, Jane DE, Sunter DC, Birse EF, Udvarhelyi PM, Watkins JC (1994) Analysis of agonist and antagonist activities of phenylglycine derivatives for different cloned metabotropic glutamate receptor subtypes. J Neurosci 14:3370-3377.

Hensch TK, Stryker MP (1996) Ocular dominance plasticity under metabotropic glutamate receptor blockade. Science 272:554-557.

Huber KM, Sawtell N, Bear MF (1996) Metabotropic glutamate receptor antagonist MCPG does not affect glutamate-stimulation phosphoinositide turnover, LTP or LTD in developing rat visual cortex. Soc Neurosci Abstr 22:276.
Joly C, Gomeza J, Brabet I, Curry K, Bockaert J, Pin J-P (1995) Molecular, functional and pharmacological characterization of the metabotropic glutamate receptor type 5 splice variants: comparison with mGluR1. J Neurosci 15:3970-3981.

Kato N, Artola A, Singer W (1991) Developmental changes in the susceptibility to long-term potentiation of neurones in rat visual cortex slices. Dev Brain Res 60:43-50.

Kirkwood A, Bear MF (1994a) Hebbian synapses in visual cortex. J Neurosci 14:1634-1645.

Kirkwood A, Bear MF (1994b) Homosynaptic long-term depression in the visual cortex. J Neurosci 14:3404-3412.

Kirkwood A, Dudek SM, Gold JT, Aizenman CD, Bear MF (1993) Common forms of synaptic plasticity in the hippocampus and neocortex in vitro. Science 260:1518-1521.

Kirkwood A, Lee H-K, Bear MF (1995) Co-regulation of long-term potentiation and experience-dependent plasticity in visual cortex by age and experience. Nature 375:328-331.

Kobayashi K, Manabe T, Takahashi T (1996) Presynaptic long-term depression at the hippocampal mossy fiber-CA3 synapse. Science 273:648-650.

Littman L, Robinson MB (1994) The effects of L-glutamate and trans-( \pm )amino-1,3-cyclopentanedicarboxylate on phosphoinositide hydrolysis can be pharmacologically differentiated. J Neurochem 63:1291-1302.

Littman L, Munir M, Flagg SD, Robinson MB (1992) Multiple mechanisms for inhibition of excitatory amino acid receptors coupled to phosphoinositide hydrolysis. J Neurochem 59:1893-1904.

Manzoni OJ, Weisskopf MG, Nicoll RA (1994) MCPG antagonizes metabotropic glutamate receptors but not long-term potentiation in the hippocampus. Eur J Neurosci 6:1050-1054.

Montague PR, Gancayco CD, Winn MJ, Marchase RB, Friedlander MJ (1994) Role of NO production in NMDA receptor-mediated neurotransmitter release in cerebral cortex. Science 263:973-977.

Oliet SHR, Malenka RC, Nicoll RA (1997) Two distinct forms of longterm depression coexist in hippocampal pyramidal cells. Neuron 18:969-982.

Pin J-P, Bockaert J (1995) Get receptive to metabotropic glutamate receptors. Curr Opin Neurobiol 5:342-349.

Reid SNM, Daw NW, Gregory DS, Flavin HJ (1996) Cyclic AMP levels increased by activation of metabotropic glutamate receptors correlate with visual plasticity. J Neurosci 16:7619-7626.

Romano C, Sesma MA, McDonald CT, O’Malley K, Van der Pol A, Olney JW (1995) Distribution of metabotropic glutamate receptor mGluR5 immunoreactivity in rat brain. J Comp Neurol 355:455-469.

Saugstad JA, Segerson TP, Westbrook GL (1995) L-2-Amino-3phosphonopropionic acid competitively antagonizes metabotropic glutamate receptors 1 alpha and 5 in Xenopus oocytes. Eur J Pharmacol 289:395-397.

Scanziani M, Salin PA, Vogt KE, Malenka RC, Nicoll RA (1997) Usedependent increases in glutamate concentration activate presynaptic metabotropic glutamate receptors. Nature 385:630-634.

Schoepp DD, Goldsworthy J, Johnson BG, Salhoff CR, Baker SR (1994) 3,5-Dihydroxyphenylglycine is a highly selective agonist for phosphoinositide-linked metabotropic receptors in the rat hippocampus. J Neurochem 63:769-772.

Schousboe A (1981) Transport and metabolism of glutamate and GABA in neurons and glial cells. Int Rev Neurobiol 22:1-45.

Selig DK, Lee H-K, Bear MF, Malenka RC (1995) Reexamination of the effects of MCPG on hippocampal LTP, LTD, and depotentiation. J Neurophysiol 74:1075-1082.

Suzdak PD, Thomsen C, Mulvihill E, Kristensen P (1994) Molecular cloning, expression, and characterization of metabotropic glutamate receptor subtypes. In: The metabotropic glutamate receptors (Conn PJ, Patel J, eds), pp 1-30. Totowa, NJ: Humana.

Testa CM, Catania MV, Young AB (1994) Anatomical distribution of metabotropic glutamate receptors in mammalian brain. In: The metabotropic glutamate receptors (Conn PJ, Patel J, eds), pp 99-123. Totowa, NJ: Humana.

Thomas MJ, O'Dell TJ (1995) The molecular switch hypothesis fails to explain the inconsistent effects of the metabotropic glutamate receptor antagonist MCPG on long-term potentiation. Brain Res 695:45-52.

Yokoi M, Kobayashi K, Manabe T, Takahashi T, Sakaguchi I, Katsura G, Shigemoto R, Ohishi H, Nomura S, Nakamura K, Nakao K, Katsuki M, Nakanishi S (1996) Impairment of hippocampal mossy fiber LTD in mice lacking mGluR2. Science 273:645-647. 